\title{
QUATRO MOVIMENTOS COM MINEIRINHO, DE CLARICE LISPECTOR
}

Maraíza Labanca, Erick Gontijo Costa, João Rocha e Julia Panadés

Os quatro movimentos que se seguem foram escritos com Clarice Lispector, ou melhor, ao lado dela. Mais precisamente na proximidade de um de seus textos - "Crônica da morte de Mineirinho". Com passos curtos, mas precisos e persistentes ora distantes do texto, ora incrivelmente próximos, eles caminham na direção de desdobrar e construir dobras de leitura e de escrita, no meio da violência da dor causada pela morte de um facínora.

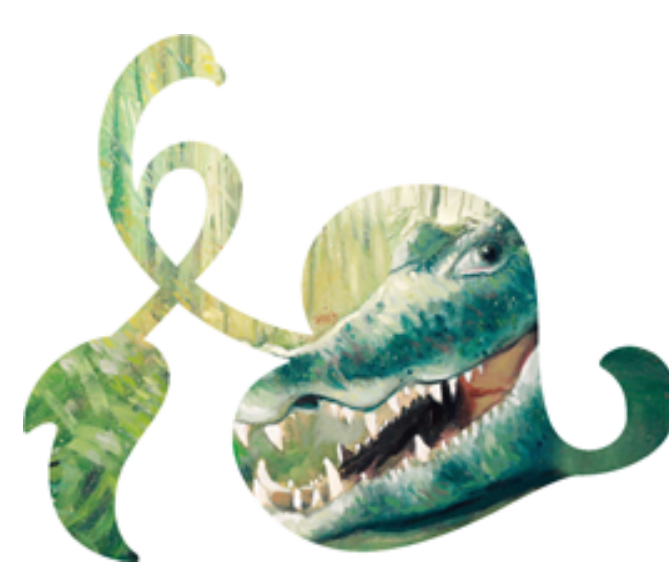


* Doutoranda em Teoria da Literatura e Literatura Comparada, na UFMG. Autora do livro de poemas Rés: o livro das contaminações, junto com Erick Gontijo Costa, publicado pela editora Cas'a'screver.

maraizalabanca@gmail.com

\section{ORIGEM, POR MARAÍZA LABANCA*}

o lugar mais calmo de um furacão é o seu olho (o centro).

ela me disse com a voz noturna.

então me falou da física, do deslocamento de ar, do tufão que dança sobre o seu eixo. a voragem da água que gira a criar um silêncio à volta, gesta o sim matricial, e

gesto é uma palavra pura.

dizia, com uma violência particular alojada nos olhos. à boca a radiância viva da frase. cresce o furacão como a turbina natural do mundo. o olho do sonho não recai sobre o dia, o mundo tende à esfera: o seu olho, um furo. ele não existe,

mas

parte os navios ao meio

dizia devagar, até que tudo escurecesse, e sua voz, de novo, era noturna.

o centro, calmo, está fora, o seu lugar mais vivo. o tufão religará o céu e a terra, reunirá as águas, o mar e as nuvens, como eram, antes do início do mundo, antes do firmamento.

é um resto da criação de deus.

\section{O REGIMENTO, POR ERICK GONTIJO COSTA*}

MÁQUINA

Tudo que há sobre esta terra foi catalogado por nossos funcionários. Descartadas as imperfeições, criamos a vida homogênea. É severamente pura, estática, lisa. Mas este homem nasceu mal feito. Insiste em movimentos imprevistos. É comprido demais, tem muitos dentes. Seus braços não cabem no ofício. Parece um saco vazio, é preciso inflá-lo pelos cantos para que se ajuste ao seu destino. É preciso esvaziar um pouco sua expectativa de vida. É preciso lhe dizer que ainda não e lhe prometer algo para que continue. Se ele não continua, toda a máquina emperra a partir do departamento de descartes de exemplares incorretos. Tentamos eliminar esse departamento, mas a máquina ainda não reconhece bem os seus circuitos. Além disso, as imperfeições proliferam incessantemente entre uma e outra engrenagem.

\section{SOBREVIVENTE}

Eu me chamo assassino; você, sobrevivente. Sou um homem à beira da morte. Não sofro de mal algum, nenhuma doença, qualquer ameaça. Estou aqui porque você vive. Por um triz, escapamos da tragédia há pouco. Sente a palpitação no peito? Se soubessem do risco, estaríamos presos, você e eu, cúmplices, minha vítima. Se soubessem do medo, nossa
* Doutor em Teoria da Literatura e Literatura Comparada, na UFMG. Autor do livro de poemas Rés: 0 livro das contaminações, junto com Maraíza Labanca, publicado pela editora Cas'a'screver.

erickgcosta@gmail.com 
companheira mais íntima gritaria, digo, a nossa condição sobrevivente, isto é, assassina.

\section{ASSASSINO}

Após bater em falso a faca sobre os dedos - ela estava já cega, jogada em um canto da casa -, hesitou. Às vezes as coisas perdem apoio, nada mais se suporta, uma bailarina sobre os calos, um copo na mão trêmula, uma folha no limite do abismo - quase caem, mas não, não é preciso matar ou ser morto nesses dias.

$$
\text { LEI }
$$

Era um homem muito rico, capaz de construir em territórios em que poucos acreditariam. Chegou mesmo a erguer duas ou três casas sobre um extenso pântano. Um engenheiro muito habilidoso, dizia-se. Mas mal podia habitar suas terras: o que era seu estava, sem motivo aparente, interditado. Chegou a ser preso algumas vezes por assinar de modo legítimo alguns documentos. Mais enriquecia, mais lhe era necessário bater às portas, em busca de comida ou abrigo Aos poucos, tornou-se esguio. Os homens da lei bateram repetidas vezes de porta em porta à sua busca. Se o encontraram acidentalmente, não o viram. As leis da cidade, mais ao fim, interditaram-se a si mesmas, quando todas as casas já estavam vazias.

\section{O TEMPO, POR JOÃO ROCHA*}

TEMPO DO NOME

-Talvez pudesse escrever o futuro e, assim, acabar com esse horror, pensou.

Pensou também que era uma frase estúpida e uma proposta inconcebível.

Pensou, porque sempre pensava seu futuro e este lhe parecia ser sempre trágico.

Por exemplo, um homem terá um filho que, vinte anos após seu nascimento, pulará do alto de um prédio sem deixar sequer um bilhete.

Coisas terríveis passavam por sua cabeça. E aí, no seu destino, morava o horror. Esse horror encontrava sua morada no futuro trágico do homem. Escrever, então, seria uma saída. Escrever construiria uma saída para o tormento. Começaria pelo futuro, pelas letras de seu nome.

- Não há lugar para o fantasma na materialidade das letras, pensou, em vão, enquanto escrevia, cuidadosamente, as letras de seu nome. (Ele não sabia, ainda, que o lugar do fantasma é justamente no engano).
* Doutorando em Teoria da Literatura e Literatura Comparada, na UFMG.

jarochabr@yahoo.com.br 
Suas lágrimas futuras vão, aos poucos, escorrendo para fora de seu nome. Escorre riacho sobre pedra. Lentamente. Silêncio de água em árida superfície.

- Nunca mais quero pensar em coisas tristes.

Mas não. Elas viriam sem que ele se desse conta. Viriam, mas o homem já havia aprendido o ofício das letras. O ofício de cantá-las, pintá-las, amá-las..

Assim: quando seu futuro o assaltava, começava por escrever as letras de seu nome para que o horror transmutasse em água a correr para fora. Para fora do nome. Seu nome. No nome residia seu destino. Morada. Desenhá-lo era escrever seu futuro. Escrevia desenhando as letras de seu nome, pois assim fazia com que o futuro retomasse seu lugar mais prosaico: o desconhecido.

Tarefa desse homem: escoar o Riohorror para fora de seu nome. Tarefa diária e árdua, pois um rio sempre lhe pareceu infinito.

\section{TEMPO DE TOCAR}

- Foi o gesto, pensou depois de alguns anos.

O gesto daquela mão que tocava a superfície do papel. Aquela mão parecia ler as letras gravadas na superfície da página. Sim. Era uma página, pois a mão tocava um livro.
Essa mão parecia ler todos os livros que o homem conhecera em sua primeira infância. Era uma mão de mulher, pois trazia em sua palma o insondável do sexo. O insondável das linhas. Destino. Sozinho, o menino podia ver. Mistério. A mão feminina corria livremente e sem medo sobre as páginas do livro, parecia conhecer o que ali se mostrava misterioso. Primeiro, ela abria o livro. Depois, deitava-se em suas páginas e, mais tarde, o menino descobriria que elas eram o seu leito. Repousava. Ali. Imóvel. Em seguida, tateava a fim de descobrir todos os cantos desse leito. Deslizava com suavidade pela superfície viva daquele corpo.

O menino, que mais tarde seria um homem, começava, aí, distante como a palma da mão, a se familiarizar com a matéria bruta de que são feitos os mistérios.

\section{TEMPO DE SABER}

- Este homem, meu Deus, sou eu.

\section{TEMPO DE VER}

A ação não se confunde com um tipo de premonição que trama a perdição como em um labirinto. Esta premonição devasta; não se pode sequer recuar. Ela tramou, um dia, o destino de um jovem prometido ao reino. Ele próprio, cegamente, assassinaria um rei; cegamente desposaria sua rainha; cegamente teria filhos com ela. Trama do interdito: o rei era 
seu pai; a rainha era sua mãe; seus filhos eram seus irmãos. A Cegueira tramou a loucura da rainha-mãe e seu caminho para a morte. A Cegueira tramou um malogro magnífico: o absurdo de ver a cegueira; o desespero diante da visão; o horror do vazio-eu. Arrancou, então, ele próprio, os olhos.

\section{O DEVIR}

Não. O homem começa a vislumbrar, ali, no momento em que escreve as letras de seu nome outro tipo de premonição que tecia uma nova e surpreendente trama: o drama.

O drama traz, em sua história, um verbo. Agir. Nesse verbo, o homem encontra um lugar, a princípio, distante. Ação. Nesse lugar, o homem entra em contato com o corpo, seu corpo, e assim, na potência de agir de um corpo, o seu corpo, ele parece escrever a letra que lhe faltava. Escreve, então, sem medo, a letra "d". Pois em face da potência de agir de um corpo o medo parece recuar. Essa letra mudaria para sempre o rumo de sua vida.

- Da trama ao drama, ele pensava.

- Da trama ao drama, escrevia.

\section{EM NOME DE}

POR JULIA PANADÉS*

Ele, de nome João, sobrenome Rocha, disse: quarta feira. Eu havia perdido um prazo. Pedi a ele um novo limite para entrega do texto, para salvar-me do adiamento, para salvar-me também do interminável nas palavras prometidas. $\mathrm{O}$ ato de dar a própria palavra - operação do termo "promessa" -, fruto de necessidade excessiva, surtida na urgência, espécie de abundância movediça em busca de corpo. Talvez por isso paga-se promessa com ex-voto. A graça empenhada naquelas imagens - promessa de cura das partes doentes esculpidas em cera e madeira, ou figuradas em pinturas e desenhos: uma mão, um pé, o ventre, os seios, as cenas do leito. E, ainda que saibamos - morre-se de um modo ou de outro, no logo ou no pós, desse mal ou daquele -, um ex-voto indica a espera ativa por alguma alteração, um acontecimento milagroso, ou graça concedida como promessa de vida. "Eu escrevo como se fosse para salvar a vida de alguém, provavelmente a minha própria vida" ${ }^{\prime}$, ex-vota-se Clarice Lispector.

Uma promessa resiste. Sua reserva está no quase: risco assegurado, como na opacidade semipedra da semente, espécie embaçada de ponto, raiz das pálpebras, lendo a extrema ponta dos cílios; uma mancha na pele, segredo de superfície
* Julia Panadés escreve e desenha diariamente. Cria livros, performances e esculturas. Envolve-se em parcerias com pessoas que também criam. Atua como professora de desenho e práticas de composição com ênfase na relação entre texto e imagem. Doutoranda em Estudos Literários pela FALE, UFMG, mestra em Artes Visuais pela EBA, UFMG e bacharel em Artes Plásticas pela Escola Guignard, UEMG.Vive em Belo Horizonte.

\section{des.net}

juliapanades@gmail.com

1. LISPECTOR, Clarice. Um sopro de vida: (pulsações). Rio de Janeiro: Francisco Alves, 1991, p.17. 
2. LISPECTOR, Clarice. Um sopro de vida: (pulsaçôes). Rio de Janeiro: Francisco Alves, 1991. p.46. que não se sabe fortuna ou doença. Entre o lance da promessa e sua realização, há um jogo do azar. É que "azar”, antes de substantivar o revés da sorte, o infortúnio, é um verbo dar azo é oferecer motivo, oportunidade. Deve-se azar como quem alça a chance no lance, pegando no ar a promessa de realização, a sensação de um pensamento. Se a velocidade do pensamento é tantas vezes fora do alcance, acolhe-se a queda, realiza-se no fracasso o sucesso da tentativa: frases meteóricas e o estrondoso choque surdo entre a linguagem e o silêncio. É como olhar a vida no olho, vemos nada (ou nada vemos?) - justamente porque ela está toda ali e para além, ofertada em seu imperceptível traje de fuga. "E eu não passo de uma promessa. Mas sou estrela. Sinto que sou estrela. Espatifada. Sou caco de vidro no chão”. ${ }^{2}$

$$
---
$$

Estou muito perto. O lance é fora de foco, não o alcanço, resta a promessa da semente como condição. $\mathrm{Na}$ opacidade escreve-se: desde quando? Eu não sei. Mas como é excessivo o sabor das frutas amadurecidas!

De volta ao começo: ele, de nome João, sobrenome Rocha, deu-me novo prazo para uma escrita, esta que aqui se põe em cena. Eu escreveria um texto para um texto de Clarice Lispector - nas "dobras de Clarice", a partir da leitura de
"Mineirinho"3. Então perguntei, para me antecipar, se poderiam ser imagens. Ele disse sim. Uma série de imagens, pensei, uma para cada tiro, como a oferenda empenhada por Ela no texto ao bandido morto. É que tenho como prática retomar frases de meus textos longos e destacá-las do contexto como metal pesado, no deslize para o desenho. A tipografia nela mesma, encena a forma/conteúdo da palavra, porque a forma contém e o conteúdo formula. O desenho da palavra portanto, somado ao trabalho da superfície (textura da imagem), e os limites do corpo (qualidade do material) - tudo atua no espaço da página como diagrama de forças.

Insisto num percurso pela arcada ampla das artes plásticas, sobretudo venho praticando "A nova arte de fazer livros" $^{4}$, não tão nova assim, também conhecida como Livro de Artista. Essa categoria tem o dom de acolher, literalmente, um infinito possível de páginas, modos de páginas e modos de escrita, continuidade e descontinuidade, variações e avariações, versões e subversões do objeto livro. A publicação dita "de artista" é lida como objeto de arte, porque auto-autoriza-se aos processos, desde os tradicionais até os mais inusitados, fazendo da experiência do livro algo novo. De cópia única, tiragem rara, numerada, assinada, extraordinária, portanto cara; ou inúmera, multiplicada, barata, dada ordinária. O livro "Balada”, do escritor-artista Nuno Ramos, por exemplo, é uma encadernação alva, larga, sem nenhuma
3. Crônica de Clarice Lispector publicada originalmente na revista Senhor.

4. CARRION, Ulisses. A nova arte de fazer livros. Belo Horizonte: $\mathrm{C} /$ Arte, 2011. 
5. “Nascido no México, Ulises Carrión foi poeta, artista, editor, Sibliotecário e crítico de arte. (a) do livro como suporn uso expressão artística que utiliza a página como um espaço parnativo. The New Art of Making Books, escrito em 1975, cum dos mais importantes um dos mais importantes do livro como estrutura, em que se explica a diferença que se explica a diferença textos e um escritor que faz livros." Apresentacão do livro, ivios. Apresentaça do livro, Amir Brito Calor tro estudioso do texto Cadrón radutor Copiado em 09/09/2014 /n: http:// gramatologia.blogspot.com.br/

6. CARRION, Ulises. A nova arte de fazer livros. Belo Horizonte: $\mathrm{C} /$ Arte, 2011. p. 5.

7. LISPECTOR, Clarice. Para não esquecer. Rio de Janeiro: Rocco 1999. p. 123. palavra impressa, mas atravessada em todas as páginas pelo rastro de um único tiro. Não se trata, assim, da velha arte de fazer livros, de um continente, volume semi-mudo, subordinado ao diagrama padrão de um conteúdo escrito. A diferença dessa diferença está entre um escritor que escreve textos e um escritor que faz livro. Um livro dessa "nova arte", na definição de Ulises Carrion" ${ }^{5}$ opera "uma sequência de espaços" que "também é uma sequência de momentos", espaços de tempo indeterminados. A página abre-se ao destino do instante e ao desejo de captura - como o "instante já" escrito por Clarice Lispector em "Água Viva”, ou "Sopro de vida", talvez, apenas ("pulsações").

Pois essa passou a ser minha promessa, conceber um livro de instâncias para "Mineirinho", o outro, o "também eu" de Clarice.

$$
-----
$$

Esta é a lei. Mas há alguma coisa que, se me fez ouvir o primeiro tiro com um alívio de segurança, no terceiro me deixa alerta, no quarto desassossegada, o quinto e o sexto me cobrem de vergonha, o sétimo e o oitavo eu ouço com o coração batendo de horror, no nono e no décimo minha boca está trêmula, no décimo primeiro digo em espanto o nome de Deus, no décimo segundo chamo meu irmão. O décimo terceiro tiro me assassina - porque eu sou o outro. Porque eu quero ser o outro.

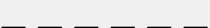

Como não cair nesse abismo que a tudo inclui e incorpora? Como mirar e cair também sem tornar-se a visão de tudo? Como ver o abismo com olhos de superfície? Talvez o lance me ultrapasse, talvez eu não o alcance. Talvez na distância more o parapeito, e operar nas "dobras de Clarice" possa ser um reparo cuidadoso nas bordas do abismo. Se me extremo demais na miragem, visita-me o poeta menino que morreu antes de escrever, antes mesmo de falar, então escrevo para salvar sua mudez e dizer em nome de , $_{\text {, numa extrema ne- }}$ cessidade infantil. Toda a ressonância com Clarice pela via da palavra, essa vertigem clarividente, é muito perigosa, porque "uma palavra", diz Paul Valery, "é um abismo sem fim." Ela ecoa longe, os termos perdem seus contornos, como acontece à minha distância crítica - quando ampla, preservo-me, sou habitante de mim mesma; quando desfeita, deserto-me no movediço das proximidades onde tudo me é próprio.

Pensei em treze papéis de algodão, de superfície densa e um pouco áspera, cortados no mesmo formato - quadrados com $13 \mathrm{~cm}$ de lado. E os desenhos feitos com pólvora, um buraco para cada tiro de modo acumulativo: o primeiro desenho com um, o segundo com dois, o terceiro com três, até que o último desenho somasse todos os treze furos. E então
8. VALERY, Paul. Variedades. São Paulo: lluminuras, 1991, p. 63. 
9. LISPECTOR, Clarice. Para não esquecer. Rio de Janeiro: Rocco, 1999. p. 123.

10. LISPECTOR, Clarice. Entrevistas. Rio de Janeiro: Beco do Azougue, 2011. p.178. eu refaria as superfícies esburacadas com agulha e linha, cerzindo uma trama nas bordas da pólvora, até reparar tudo.

$$
--------
$$

"É, suponho que é em mim, como um dos representantes de nós, que devo procurar por que está doendo a morte de um facínora." Assim começa a crônica de Clarice Lispector escrita em 1962. Quinze anos depois, naquele que seria o ano de sua própria morte, Ela aceitou ser entrevistada por uma emissora de TV pela primeira vez. $\mathrm{Na}$ entrevista, quando perguntada qual, dentre seus diversos trabalhos, é o que "vê com maior carinho até hoje", Ela responde: "Uma coisa que eu escrevi sobre um bandido, sobre um criminoso, chamado Mineirinho, que morreu com treze balas quando uma só bala bastava e que era devoto de São Jorge e tinha uma namorada e que me deu uma revolta enorme e escrevi isso". ${ }^{10}$

Li "Mineirinho" na medida selvagem de leitura que costumo acionar quando há urgência. Normalmente tomo o texto como meu, e sem pudor, para nutrir a escrita com um vandalismo teórico que funciona muito bem desde que eu seja dispensada de um discurso especialista, forjado "sobre" alguma coisa, empostando o domínio da questão e a nitidez do objeto. Assim, escrevo como leio, no limite da minha ignorância, e movo-me na perplexidade do encontro com algo que chega, como na encomenda do João. Desdobrar "a partir" das frestas, das aberturas, do espaço que me diz respeito, solicita atenção, assusta e mete medo. Vou com medo mesmo, no risco dos excessos empenhados "em nome de", como se meu profeta estivesse a todo tempo por nascer. Dada a liberdade de ver oscilarem as distâncias que o pensamento lança, alcança, fracassa, na leitura selvagem, leio como quem escreve, deixando o texto correr sem freio, e no vandalismo teórico, escrevo como quem lê, fazendo as alianças nas curvas, nas cavas, nas covas rasas, talvez cantos, e uma prece.

Ela, "como um dos representantes de nós", pergunta-se: "por que está me doendo a morte de um facínora?" Clarice curva-se em "Mineirinho" - "como não amá-lo" em sua "assustada violência"?. Em "sua violência inocente - não nas consequências, mas em si inocente como a de um filho de quem o pai não tomou conta." ${ }^{11}$ Se estamos erguidos e alimentados, se comemos e dormimos no acolhimento burguês de um pequeno mundo, "o que nele foi violência é em nós furtivo, e um evita o olhar do outro para não corrermos o risco de nos entendermos. Para que a casa não estremeça"12 na ressonância de uma mesma massa óssea. É como se nossas diferenças, altivas, rastejantes, descalças, sobre o salto, no coturno, no cadarço, não nos convertessem, no fundo dos ossos, em iguais. Restamos iguais. Como uma ameaça
11. LISPECTOR, Clarice. Para não esquecer. Rio de Janeiro: Rocco, 1999. p. 124.

12. LISPECTOR, Clarice. Para não esquecer. Rio de Janeiro: Rocco, 1999. p. 124 
13. LISPECTOR, Clarice. Para não esquecer. Rio de Janeiro: Rocco, 1999. p. 125.

14. LISPECTOR, Clarice. Entrevistas. Rio de Janeiro: Beco do Azougue, 2011. p.179.

15. LISPECTOR, Clarice. Para não esquecer. Rio de Janeiro: Rocco, 1999. p. 125. dessa desproporção se repete? Como não se/nos autorrepele? Como torna-se legítima? Como não convulsiona em bumerangue punhos, canetas, armas, mãos que deliberadamente violentam, assinam, atiram?

$$
-----------
$$

"Como não amá-lo se ele viveu até o décimo terceiro tiro o que eu dormia?" 13 No estreitamento das distâncias, contamos com Ela a soma do último tiro, sua carne atingida recebe a sobra, protegendo a visão do corpo morto, como um manto, nossa sombra desumana pousa inerte sobre o massacre "quando uma bala só bastava"14. Clarice é "Mineirinho", porque quer ser o outro, salvar a inocência pisada, recolher "sua assustada violência" como a uma semente e plantá-la, para erguer dela uma (outra) casa, habitada em terra viva.

Qual palavra/prece emerge nessa revolta imensa, quase inútil, de tanto amor ao bandido morto? Rumo a qual necessidade o empenho de Clarice nos clama? Nós, os "sonsos essenciais"15. A que nos lança a escrita de "Mineirinho"? De qual anterioridade póstuma ecoa? De qual necessidade a promessa se faz destinatária?

\section{$-----------$}

Uma justiça prévia que se lembrasse de que nossa grande luta é a do medo, e que um homem que mata muito é porque teve mui- to medo. (...) Uma justiça que não se esqueça de que nós todos somos perigosos, e que na hora em que o justiceiro mata, ele não está mais nos protegendo nem querendo eliminar um criminoso, ele está cometendo o seu crime particular, um longamente guardado. Na hora de matar um criminoso - nesse instante está sendo morto um inocente. Não, não é que eu queira o sublime, nem as coisas que foram se tornando as palavras que me fazem dormir tranquila, mistura de perdão, de caridade vaga, nós que nos refugiamos no abstrato. A inocência sem nome?

O que eu quero é muito mais áspero e difícil: eu quero o terreno. ${ }^{16}$

$$
------------
$$

Ao ouvir Clarice dizer: "eu escrevo sem esperança de que o que eu escrevo altere alguma coisa. Não altera nada”, o repórter Júlio Lerner pergunta: "por que continuar escrevendo?" Ela responde espantada: "E eu sei? Porque no fundo a gente não está querendo alterar as coisas. A gente está querendo é desabrochar, de um modo ou de outro, né? o que a gente quer mesmo é desabrochar" ${ }^{\prime 17}$. Simples como um "Mineirinho", relevo mal nutrido de matéria férrea, parido anêmico entre a terra vermelha e o barranco argiloso do rio, sem saber que corria a ser desfeito à margem sem nome do imenso mar, o rio dos rios. Um pássaro divino contou-me era uma vez uma montanha qualquer que se desprendeu
16. LISPECTOR, Clarice. Para não esquecer. Rio de Janeiro: Rocco, 1999. p. 126.

17. LISPECTOR, Clarice. Entrevistas. Rio de Janeiro: Beco do Azougue, 2011. p.179. 
louca, em transe, erodida, pulverizada, "essa coisa é um grão de vida que se for pisado se transforma em algo ameaçador." Eram treze montanhas, sustenta-me dizer: a última era eu.

\section{Julia Panadés}

para a revista Em tese, PosLit - UFMG, Belo Horizonte, 09/2014.

\section{REFERÊNCIAS}

CARRION, Ulisses. A nova arte de fazer livros. Trad. Amir Brito Cadôr. Belo Horizonte: C/Arte, 2011.

LISPECTOR, Clarice. Água Viva. Rio de Janeiro: Rocco, 1998

Um sopro de vida: (pulsações). Rio de Janeiro: Francisco Alves, 1991

, Para não esquecer. Rio de Janeiro: Rocco, 1999.

Entrevistas. Org. Evelyn Rocha. Rio de Janeiro: Beco do Azougue, 2011

VALERY, Paul. Variedades. Org. João Alexandre Barbosa. Trad. Maiza Martins Siqueira. São Paulo: lluminuras, 1991.

Houaiss, Dicionário online http://houaiss.uol.com.br/

Entrevista de Clarice Lispector na TV Cultura, vídeo consultado em 09/09/2014: http://www.youtube.com/ watch?v=ohHP1/2EVnU 